\title{
ANALYZING AND PROPOSING DIFFERENT MODULES OF ORGANIZATIONAL STRUCTURES FOR MEDIUM SCALE CONSTRUCTION PROJECTS IN INDIAN SCENARIO
}

\author{
Madonna Jasmine J $\mathbf{U}^{1}$, Praveen $\mathrm{K} \mathrm{S}^{\mathbf{2}}$ \\ ${ }^{1} P G$ Student, Department of Civil Engineering, SRM University, Tamil Nadu, India \\ ${ }^{2}$ Assistant Professor, Department of Civil Engineering, SRM University, Tamil Nadu, India
}

\begin{abstract}
This case study focuses on the efficiency of the existing organizational structure for a medium scale construction projects. The changes required for the betterment of the organization is highlighted and an improved organizational structure is proposed. The organizational structure of the project is studied and the project network is developed based on the activities of work carried out on the construction project. By using the Benningson's Trend Modeling method, activity relationship matrix(ARM) and communication relationship Matrix (CRM) is constructed. The number of handovers between members is shown in ARM. The ARM is based on the successor activity and precedent activity of the project network. The efficiency of communication and coordination between the members of the project is determined in communication resistance matrix. The optimal organizational structure is determined by total resistance index which is calculated from total resistance matrix. This study is aimed to determine the efficiency of existing organizational structure through quantitative modeling and by making necessary changes in the structure for the betterment of the organization.
\end{abstract}

Keywords: Construction, project network1, Trend modeling2, Activity Relationship3, Communication resistance4, Total resistance index5, efficiency6, task allocation 7 and Optimal Organizational Structure8 etc...

\section{INTRODUCTION}

An organizational structure defines how activities such as task allocation, co-ordination and supervision are directed towards the achievement of organizational aims. The organizational chart is often ill-structured in many organizations. Therefore there is a need to study the efficiency of existing structure and make the necessary changes for the betterment of the organization. An organization can be structured in many different ways depending on their objectives. The objective of this study is to investigate the efficiency of the exising organizational structure for construction projects and to determine the optimal organizational structure based on the results obtained from various matrix calculations.

The organization team of a construction project is divided into two types.

a) Administration team

b) Execution team

The administration team is composed of members of the top management level. The execution team includes main contractor, sub-contractors, supervisors, labours, etc. The activities of work of the project is carried out by the execution team.

Previously a case study has been done on a wharf construction project within the port for the establishment of a well coordinated organizational structure by Min-Yuan
Cheng, Cheng-Wei su and Horng-Yuh You. This paper focuses on evaluating the efficiency of the organizational structure of the execution team of medium scale construction projects in Indian scenario. The residential construction projects were selected as the case study of this approach.

\section{METHODOLOGY}

The methodology used in this study was both qualitative and quantitative since the procedure includes personal interviews with the managers and manual matrix calculations.

First a thorough study of the project characteristics which includes project organizational structure, activities of work, members of the construction team, members involved in the activities of work etc. should be done which is the basis for the calculation of the ARM and CRM and to determine the optimal organizational structure.

Based on the activities of work, the project network is plotted. The number of handovers between the members can be determined from the project network which can be presented in the Activity Relationship matrix. The preceding and succeeding activity relationship and also the potential superior of the member is also determined from the project network. 
The next step is drawing the possible organizational structures. The present project organizational structure is drawn based on the personal interviews with the manager and then various possible alternatives of organizational structure is proposed.

After drawing all the alternatives the CRM for each alternative is determined. The CRM is drawn based on communication resistance values from $\mathrm{k} 1$ to $\mathrm{k} 6$. To prevent over complexity of the structure, the layers of the organizational structure should be limited to three. The communication resistance values $\mathrm{k} 1$ to $\mathrm{k} 6$ are given for each layer where ,

$\mathrm{k} 1$ - resistance of top member to the members of first layer

$\mathrm{k} 2$ - resistance of members from first layer to second layer

$\mathrm{k} 3$ - resistance of members from second layer to third layer

$\mathrm{k} 4$ - resistance of members from third layer to second layer

$\mathrm{k} 5$ - resistance of members from second layer to first layer

k6- resistance of members from first layer to the top member

A questionnaire survey was conducted in the previous research which was carried out on a wharf construction project by Min-Yuan Cheng, Cheng-Wei su and Horng-Yuh You to determine the values of $\mathrm{k} 1$ to $\mathrm{k} 6$ using the Analytical Hierarchy Process .

$\mathrm{k} 1=0.11$

$\mathrm{k} 2=0.12$

$\mathrm{k} 3=0.13$

$\mathrm{k} 4=0.20$

$\mathrm{k} 5=0.22$

$\mathrm{k} 6=0.23$

These values are used in this case study to determine the communication resistance matrix. After calculating CRM ,the Total Resistance Matrix is determined by multiplying ARM and CRM.

Total Resistance Matrix = Activity Relationship Matrix $\mathrm{x}$ Communication Resistance Matrix

Therefore the Total Resistance Index (TRI) is the sum of all the components of the Total Resistance Matrix. In the same manner the Total Resistance Index of each alternatives of the organizational structure is calculated. The organizational structure which has the smallest value of TRI is considered to be the optimal organizational structure.

\section{ANALYSIS AND RESULTS}

Based on the methodology described before, a medium scale construction industry has been selected for the case study of this approach. Its analysis by means of quantitative method is described below.

\subsection{Medium Scale Industry}

The datas for this case study were obtained from a medium scale construction project located at Trivandrum in the state of Kerala. Its turnover is around 10 crores.

\subsubsection{Members of the Construction Team}

The members involved in this construction project for the execution of work are listed below.

1. Managing Director (MD) 2. Project Engineer(PE) 3. Accounts Manager (AM) 4. Store Manager (SM) 5. Site supervisors (SS) 6. Accounting Clerk (AC) 7. Store Keeper (SK) 8.Masons (M) 9. Helper (H) 10. Shuttering Carpenter (S) 11. Bar Benders (B)

\subsubsection{Project Organizational Structure}

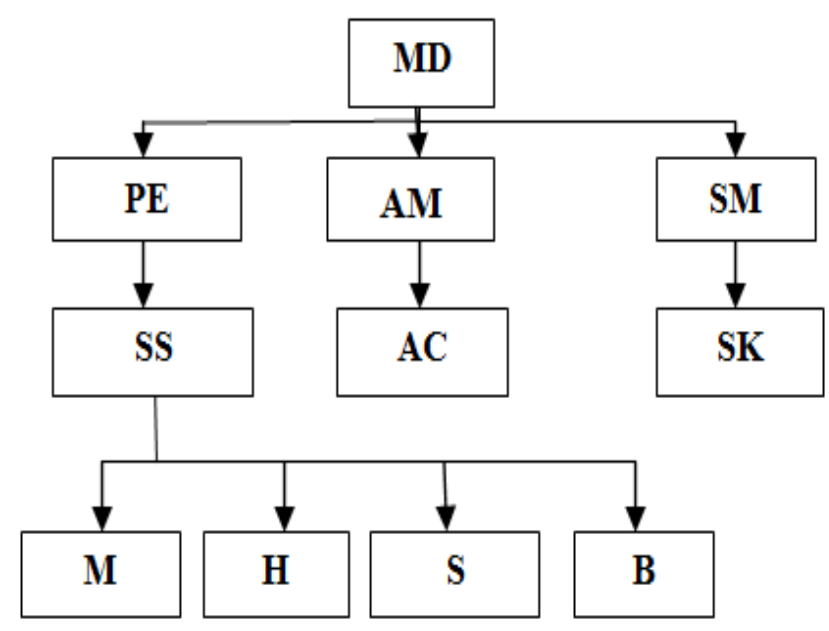

Fig-1: Project Organizational Structure

\subsubsection{Activities of Work}

1.Plinth Beam 2.Column Reinforcement 3.Tying of Reinforcement 4.Shuttering 5.Concreting (RCC) 6.Staging and Shuttering of roof beam and slab 7.Reinforcement tying of beam and slab of roof 8.RCC works (M25) 9.Staircase shuttering of waist slab and steps 10.Reinforcement of waist slab and steps 11.RCC of waist slab and steps (M20) 12.Brickwork of walls 13.Sand filling in floors 14.PCC 15.Plastering of walls 16.Flooring 17.Fixing of staircase hand railing 18.Parapet wall works 19. Waterproofing works These are the activities of work involved in this construction project. Based on these activities Activity relationship Matrix, Preceding/ Succeeding Activity Relationship and Probable Layer Relationship are determined.

\subsubsection{Project Network}

The project network is drawn based on the activities of work in this project. The relationship between activities and the whole construction sequence should be specified and shown on the network drawing to facilitate development of the ARM. The project network of this project is shown in Fig 2. 


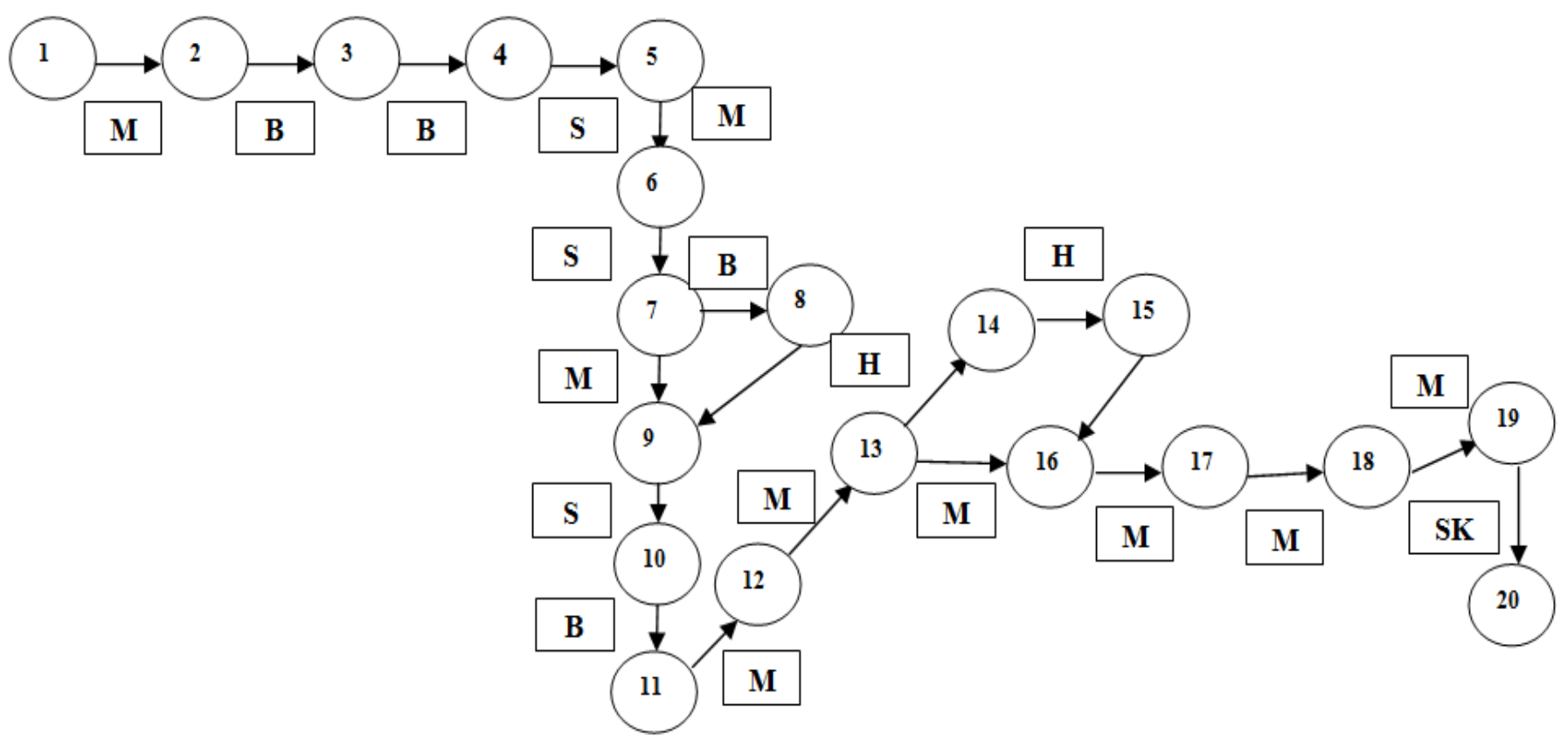

Fig- 2: Project Network

\subsubsection{Activity Relationship Matrix (ARM)}

The Activity Relationship Matrix for the present structure is given in Table 1.

Table- 1: Activity Relationship Matrix

\begin{tabular}{|c|c|c|c|c|c|c|c|c|c|c|c|}
\hline & \multicolumn{10}{|c|}{ SUCCESS ACTIVITY } \\
\hline & & $\mathbf{P E}$ & SS & $\mathbf{M}$ & $\mathbf{H}$ & $\mathbf{S}$ & B & $\mathbf{A M}$ & $\mathbf{A C}$ & SM & SK \\
\hline \multirow{10}{*}{ 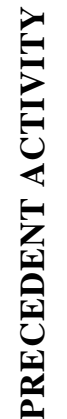 } & PE & 0 & 0 & 0 & 0 & 0 & 0 & 0 & 0 & 0 & 0 \\
\hline & SS & 0 & 0 & 0 & 0 & 0 & 0 & 0 & 0 & 0 & 0 \\
\hline & $\mathbf{M}$ & 0 & 0 & 6 & 1 & 2 & 1 & 0 & 0 & 0 & 1 \\
\hline & $\mathbf{H}$ & 0 & 0 & 1 & 1 & 0 & 0 & 0 & 0 & 0 & 0 \\
\hline & $\mathbf{S}$ & 0 & 0 & 2 & 0 & 0 & 2 & 0 & 0 & 0 & 0 \\
\hline & B & 0 & 0 & 1 & 0 & 2 & 1 & 0 & 0 & 0 & 0 \\
\hline & AM & 0 & 0 & 0 & 0 & 0 & 0 & 0 & 0 & 0 & 0 \\
\hline & $\mathbf{A C}$ & 0 & 0 & 0 & 0 & 0 & 0 & 0 & 0 & 0 & 0 \\
\hline & SM & 0 & 0 & 0 & 0 & 0 & 0 & 0 & 0 & 0 & 0 \\
\hline & SK & 0 & 0 & 0 & 0 & 0 & 0 & 0 & 0 & 0 & 0 \\
\hline
\end{tabular}

From the construction sequence shown on the network in fig 2, the number of hand-overs between the members can be found and presented in a matrix. The table shows that the Helper receives work from Mason once whereas Site Supervisor never receives any work from Mason. The Activity Relationship Matrix for the present structure is given in Table 1.

\subsubsection{Communication Resistance Matrix (CRM)}

The communication resistance between members is represented in Communication Resistance Matrix. For example, if the Project Engineer wants to communicate with the mason, he should first pass the message to the Site supervisors and the Site supervisors will inform to the mason. And so in the Communication Resistance Matrix between PE and $M$ the resistance will be $k 2+k 3$. In this manner, effective communication between members in a project is carried out. The values of CRM can be determined by substituting the corresponding values of $\mathrm{k} 1$ to $\mathrm{k} 6$ as discussed earlier and is shown in Table 3 .

\subsubsection{Total Resistance Index (TRI)}

The Total Resistance Matrix is the product of Activity Relationship Matrix and Communication Resistance Matrix. The Total Resistance Matrix of this case study is described in Table 4.

Here Total Resistance Index $(\mathrm{TRI})=$ Sum of all the components of $\mathrm{T} \mathrm{mn} \sum \mathrm{Tmn}$

$=0.33+0.66+0.33+0.81+0.33+0.66+0.66+0.33+0.66$ $=4.77$ 
The organizational structure with least value of Total Resistance Index is the optimum organizational structure. In the similar manner, the Communication Resistance Matrix and Total Resistance Index is determined for various alternatives.

\subsubsection{Various Alternatives and their TRI}

The least value of Total Resistance Index determined among all the alternatives of organizational structure is the optimum organizational structure. The various alternatives are given below.

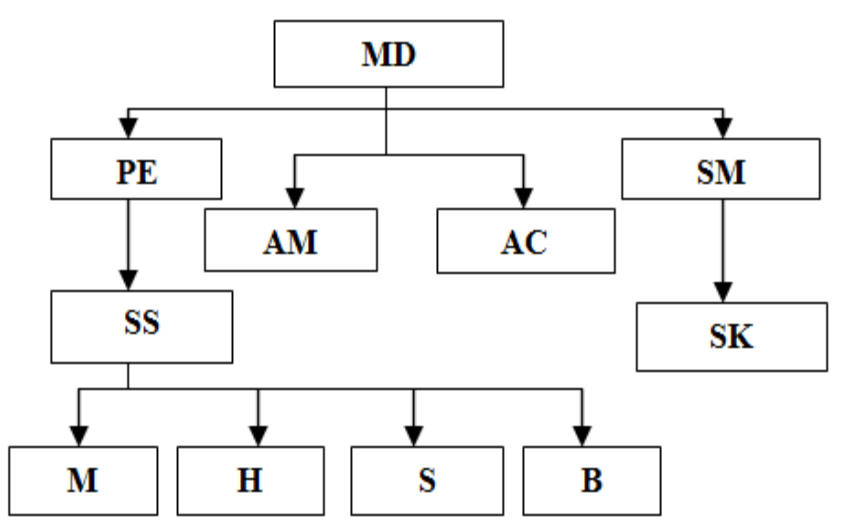

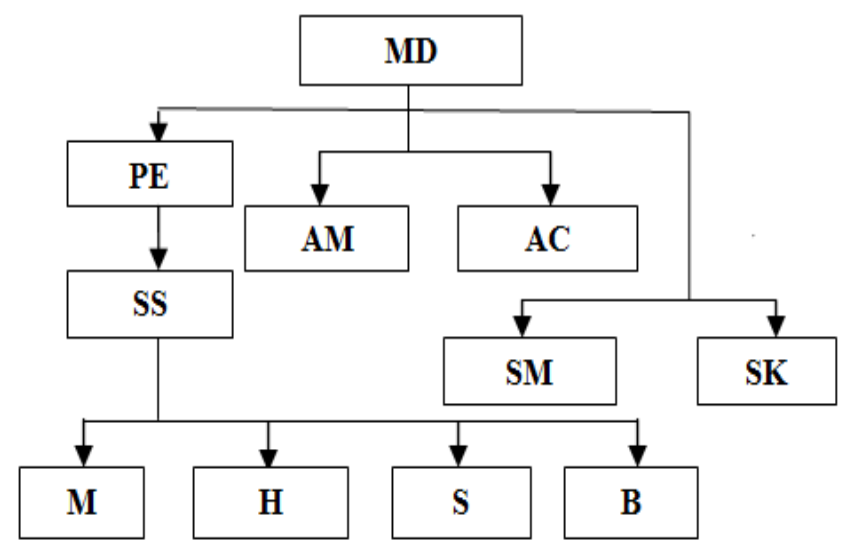

Fig-4: Alternative 2

The Total Resistance Index of these various alternatives are listed below.

Table -2: Total Resistance Index

\begin{tabular}{|l|l|}
\hline \multicolumn{2}{|l|}{ Total Resistance Index } \\
\hline Alternative 1 & 4.86 \\
\hline Alternative 2 & 4.55 \\
\hline
\end{tabular}

Fig-3: Alternative 1

Table -3: Communication Resistance Matrix using resistance coefficient

\begin{tabular}{|c|c|c|c|c|c|c|c|c|c|c|}
\hline & \multicolumn{10}{|c|}{ COMMUNICATION RESISTANCE MATRIX } \\
\hline & PE & SS & $\mathbf{M}$ & $\mathbf{H}$ & $\mathbf{S}$ & B & AM & $\mathbf{A C}$ & SM & SK \\
\hline PE & 0 & K5 & $\mathrm{K} 4+\mathrm{K} 5$ & $\mathrm{~K} 4+\mathrm{K} 5$ & $\mathrm{~K} 4+\mathrm{K} 5$ & $\mathrm{~K} 4+\mathrm{K} 5$ & $\mathrm{~K} 1+\mathrm{K} 6$ & $\begin{array}{l}\mathrm{K} 1+\mathrm{K} 5+ \\
\mathrm{K} 6\end{array}$ & $\mathrm{~K} 1+\mathrm{K} 6$ & $\begin{array}{l}\mathrm{K} 1+\mathrm{K} 5+ \\
\mathrm{K} 6\end{array}$ \\
\hline SS & K2 & 0 & K4 & K4 & K4 & K4 & $\begin{array}{l}\mathrm{K} 1+\mathrm{K} 2 \\
+\mathrm{K} 6\end{array}$ & $\begin{array}{l}\mathrm{K} 1+\mathrm{K} 2+ \\
\mathrm{K} 5+\mathrm{K} 6\end{array}$ & $\begin{array}{l}\mathrm{K} 1+\mathrm{K} 2+ \\
\mathrm{K} 6\end{array}$ & $\begin{array}{l}\mathrm{K} 1+\mathrm{K} 2+ \\
\mathrm{K} 5+\mathrm{K} 6\end{array}$ \\
\hline $\mathbf{M}$ & $\mathrm{K} 2+\mathrm{K} 3$ & K3 & 0 & $\mathrm{~K} 3+\mathrm{K} 4$ & $\mathrm{~K} 3+\mathrm{K} 4$ & $\mathrm{~K} 3+\mathrm{K} 4$ & $\begin{array}{l}\mathrm{K} 1+\mathrm{K} 2 \\
+\mathrm{K} 3+ \\
\mathrm{K} 6\end{array}$ & $\begin{array}{l}\mathrm{K} 1+\mathrm{K} 2+ \\
\mathrm{K} 3+\mathrm{K} 5+ \\
\mathrm{K} 6\end{array}$ & $\begin{array}{l}\mathrm{K} 1+\mathrm{K} 2+ \\
\mathrm{K} 3+\mathrm{K} 6\end{array}$ & $\begin{array}{l}\mathrm{K} 1+\mathrm{K} 2+ \\
\mathrm{K} 3+\mathrm{K} 5+ \\
\mathrm{K} 6\end{array}$ \\
\hline $\mathbf{H}$ & $\mathrm{K} 2+\mathrm{K} 3$ & K3 & $\mathrm{K} 3+\mathrm{K} 4$ & 0 & $\mathrm{~K} 3+\mathrm{K} 4$ & $\mathrm{~K} 3+\mathrm{K} 4$ & $\begin{array}{l}\mathrm{K} 1+\mathrm{K} 2 \\
+\mathrm{K} 3+ \\
\mathrm{K} 6\end{array}$ & $\begin{array}{l}\mathrm{K} 1+\mathrm{K} 2+ \\
\mathrm{K} 3+\mathrm{K} 5+ \\
\mathrm{K} 6\end{array}$ & $\begin{array}{l}\mathrm{K} 1+\mathrm{K} 2+ \\
\mathrm{K} 3+\mathrm{K} 6\end{array}$ & $\begin{array}{l}\mathrm{K} 1+\mathrm{K} 2+ \\
\mathrm{K} 3+\mathrm{K} 5+ \\
\mathrm{K} 6\end{array}$ \\
\hline $\mathbf{S}$ & $\mathrm{K} 2+\mathrm{K} 3$ & K3 & $\mathrm{K} 3+\mathrm{K} 4$ & $\mathrm{~K} 3+\mathrm{K} 4$ & 0 & $\mathrm{~K} 3+\mathrm{K} 4$ & $\begin{array}{l}\mathrm{K} 1+\mathrm{K} 2 \\
+\mathrm{K} 3+ \\
\mathrm{K} 6\end{array}$ & $\begin{array}{l}\mathrm{K} 1+\mathrm{K} 2+ \\
\mathrm{K} 3+\mathrm{K} 5+ \\
\mathrm{K} 6\end{array}$ & $\begin{array}{l}\mathrm{K} 1+\mathrm{K} 2+ \\
\mathrm{K} 3+\mathrm{K} 6\end{array}$ & $\begin{array}{l}\mathrm{K} 1+\mathrm{K} 2+ \\
\mathrm{K} 3+\mathrm{K} 5+ \\
\mathrm{K} 6\end{array}$ \\
\hline B & $\mathrm{K} 2+\mathrm{K} 3$ & K3 & $\mathrm{K} 3+\mathrm{K} 4$ & $\mathrm{~K} 3+\mathrm{K} 4$ & $\mathrm{~K} 3+\mathrm{K} 4$ & 0 & $\begin{array}{l}\mathrm{K} 1+\mathrm{K} 2 \\
+\mathrm{K} 3+ \\
\mathrm{K} 6\end{array}$ & $\begin{array}{l}\mathrm{K} 1+\mathrm{K} 2+ \\
\mathrm{K} 3+\mathrm{K} 5+ \\
\mathrm{K} 6\end{array}$ & $\begin{array}{l}\mathrm{K} 1+\mathrm{K} 2+ \\
\mathrm{K} 3+\mathrm{K} 6\end{array}$ & $\begin{array}{l}\mathrm{K} 1+\mathrm{K} 2+ \\
\mathrm{K} 3+\mathrm{K} 5+ \\
\mathrm{K} 6\end{array}$ \\
\hline AM & $\mathrm{K} 1+\mathrm{K} 6$ & $\begin{array}{l}\text { K1+K5 } \\
+\mathrm{K} 6\end{array}$ & $\begin{array}{l}\text { K1+K4+ } \\
\text { K5+K6 }\end{array}$ & $\begin{array}{l}\text { K1+K4+ } \\
\text { K5+K6 }\end{array}$ & $\begin{array}{l}\text { K1+K4+ } \\
\text { K5+K6 }\end{array}$ & $\begin{array}{l}\text { K1+K4 } \\
+\mathrm{K} 5+ \\
\text { K6 }\end{array}$ & 0 & K5 & $\mathrm{K} 1+\mathrm{K} 6$ & $\begin{array}{l}\text { K1+K5+ } \\
\text { K6 }\end{array}$ \\
\hline$\overline{A C}$ & $\begin{array}{l}\mathrm{K} 1+\mathrm{K} 2 \\
+\mathrm{K} 6\end{array}$ & $\begin{array}{l}\mathrm{K} 1+\mathrm{K} 2 \\
+\mathrm{K} 5+ \\
\mathrm{K} 6\end{array}$ & $\begin{array}{l}\text { K1+K2+ } \\
\text { K4+K5+ } \\
\text { K6 }\end{array}$ & $\begin{array}{l}\text { K1+K2+ } \\
\text { K4+K5+ } \\
\text { K6 }\end{array}$ & $\begin{array}{l}\text { K1+K2+ } \\
\text { K4+K5+ } \\
\text { K6 }\end{array}$ & $\begin{array}{l}\mathrm{K} 1+\mathrm{K} 2 \\
+\mathrm{K} 4+\mathrm{K} \\
5+\mathrm{K} 6\end{array}$ & K2 & 0 & $\begin{array}{l}\mathrm{K} 1+\mathrm{K} 2+ \\
\mathrm{K} 6\end{array}$ & $\begin{array}{l}\mathrm{K} 1+\mathrm{K} 2+ \\
\mathrm{K} 5+\mathrm{K} 6\end{array}$ \\
\hline SM & $\mathrm{K} 1+\mathrm{K} 6$ & $\begin{array}{l}\mathrm{K} 1+\mathrm{K} 5 \\
+\mathrm{K} 6\end{array}$ & $\begin{array}{l}\text { K1+K4+ } \\
\text { K5+K6 }\end{array}$ & $\begin{array}{l}\text { K1+K4+ } \\
\text { K5+K6 }\end{array}$ & $\begin{array}{l}\text { K1+K4+ } \\
\text { K5+K6 }\end{array}$ & $\begin{array}{l}\mathrm{K} 1+\mathrm{K} 4 \\
+\mathrm{K} 5+ \\
\mathrm{K} 6\end{array}$ & $\mathrm{~K} 1+\mathrm{K} 6$ & $\begin{array}{l}\text { K1+K5+ } \\
\text { K6 }\end{array}$ & 0 & K5 \\
\hline SK & $\begin{array}{l}\mathrm{K} 1+\mathrm{K} 2 \\
+\mathrm{K} 6\end{array}$ & $\begin{array}{l}\text { K1+K2 } \\
+\mathrm{K} 5+ \\
\text { K6 }\end{array}$ & $\begin{array}{l}\mathrm{K} 1+\mathrm{K} 2+ \\
\mathrm{K} 4+\mathrm{K} 5+ \\
\mathrm{K} 6\end{array}$ & $\begin{array}{l}\mathrm{K} 1+\mathrm{K} 2+ \\
\mathrm{K} 4+\mathrm{K} 5+ \\
\mathrm{K} 6\end{array}$ & $\begin{array}{l}\mathrm{K} 1+\mathrm{K} 2+ \\
\mathrm{K} 4+\mathrm{K} 5+ \\
\mathrm{K} 6\end{array}$ & $\begin{array}{l}\mathrm{K} 1+\mathrm{K} 2 \\
+\mathrm{K} 4+\mathrm{K} \\
5+\mathrm{K} 6\end{array}$ & $\begin{array}{l}\mathrm{K} 1+\mathrm{K} 2 \\
+\mathrm{K} 6\end{array}$ & $\begin{array}{l}\mathrm{K} 1+\mathrm{K} 2+ \\
\mathrm{K} 5+\mathrm{K} 6\end{array}$ & K2 & 0 \\
\hline
\end{tabular}


Table- 4: Total Resistance Matrix (ARM x CRM)

\begin{tabular}{|l|l|l|l|l|l|l|l|l|l|l|}
\hline & \multicolumn{1}{|l}{ TOTAL RESISTANCE MATRIX } \\
\cline { 2 - 12 } & PE & SS & M & H & S & B & AM & AC & SM & SK \\
\hline PE & 0 & 0 & 0 & 0 & 0 & 0 & 0 & 0 & 0 & 0 \\
\hline SS & 0 & 0 & 0 & 0 & 0 & 0 & 0 & 0 & 0 & 0 \\
\hline M & 0 & 0 & 0 & 0.33 & 0.66 & 0.33 & 0 & 0 & 0 & 0.81 \\
\hline H & 0 & 0 & 0.33 & 0 & 0 & 0 & 0 & 0 & 0 & 0 \\
\hline S & 0 & 0 & 0.66 & 0 & 0 & 0.66 & 0 & 0 & 0 & 0 \\
\hline B & 0 & 0 & 0.33 & 0 & 0.66 & 0 & 0 & 0 & 0 & 0 \\
\hline AM & 0 & 0 & 0 & 0 & 0 & 0 & 0 & 0 & 0 & 0 \\
\hline AC & 0 & 0 & 0 & 0 & 0 & 0 & 0 & 0 & 0 & 0 \\
\hline SM & 0 & 0 & 0 & 0 & 0 & 0 & 0 & 0 & 0 & 0 \\
\hline SK & 0 & 0 & 0 & 0 & 0 & 0 & 0 & 0 & 0 & 0 \\
\hline
\end{tabular}

The values of the Total Resistance Matrix can be found out by multiplying Activity Relationship Matrix and Communication Resistance Matrix. The sum of all the values of Total Resistance Matrix is Total Resistance Index.

\subsubsection{Optimal Organizational Structure}

After the TRI for each possible organization structure is calculated, the one with the smallest value is determined to be the optimal organizational structure. Here the smallest Total Resistance Index Value is of Alternative 2 i.e) 4.55. Hence Alternative 2 is the optimal organizational Structure.The Optimal Organizational Structure is given in Figure 5 below.

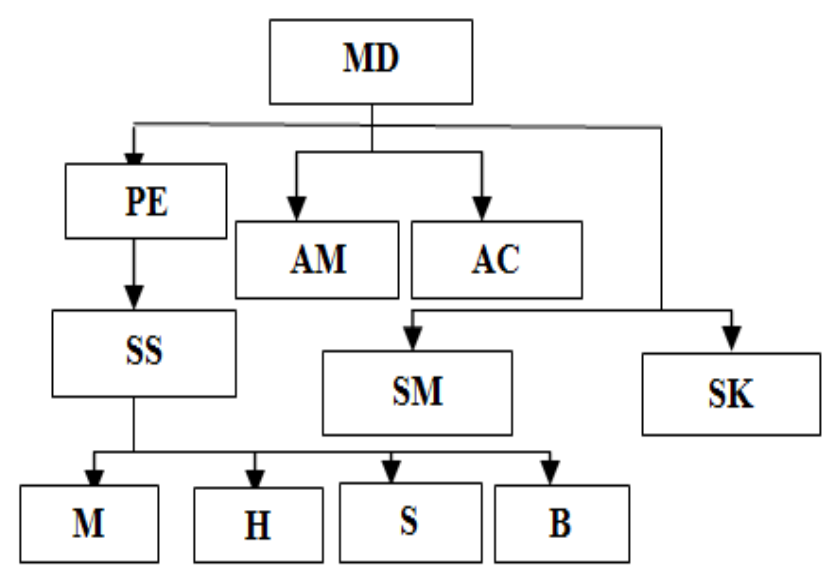

Fig 5:- Optimal Organizational Structure

\section{CONCLUSION}

This study uses the quantitative evaluation to determine the optimal organizational structure. Based on this case study, it is found that the organizational structure must be well selected before starting execution. The manager must readjust the organizational structure in the construction planning phase to improve the efficiency of the existing organizational structure. In this paper, the optimal organizational structure of the large scale construction project in India is determined by qualitative and quantitative analysis. It was found out that the structures which possess ease in communication between the members, forms the optimal organizational structure.

\section{REFERENCES}

[1] Min-Yuan Cheng (2006), Associate Member, ASCE, Cheng-Wei $\mathrm{Su}$ and Horng- Yuh You, "Optimal Project Organizational Structure for Construction Management" .

[2] Fariza Achcaoucaou, Merce Bernardo and Jose M.Castan (2009), "Determinants of Organisational Structures,An Empirical Study” , Review of International Comparative Management, Vol.10, Issue 3, pp. 566

[3] Bernard C. Reimann (1974), "Dimensions of Structure in Effective Organizations: Some Empirical Evidence", The Academy of Management Journal,Vol.17, No.4, pp. 693-708.

[4] Johanim Johari and Khulida Kirana Yahya (2009), "Linking Organizational Structure, Job Characteristics and Job Performance Constructs: A Proposed Framework",International Journal of Business and Management, Vol.4, No.3

[5] Quangyen Tran and Yezhuang Tian(2013), "Organizational Structure: Influencing Factors and Impact on a Firm", American Journal of Industrial And Business Management, Vol.3, pp. 229-236.

[6] Ehab Elkassas, Hossam Hosny, Waleed Mattr(2013), " Optimum Organizational Structure for Construction Projects",International Journal of Engineering Science and Innovative Technology, Vol.2, Issue 3

[7] Greg R. Oldham and J. Richard Hackman (1981), "Relationships Between Organizational Structure and Employee Reactions: Comparing Alternative Frameworks", Administrative Science quarterly,Vol.26, No.1, pp.66-83 
[8] Kumudinei Dissanayake and Masayasu Takahashi (2006), "The Construction of Organizational Structure : Connections with Autopoietic Systems Theory", Contemporary Management Research. Vol.2, No.2, pp. 105-116.

\section{BIOGRAPHIES}

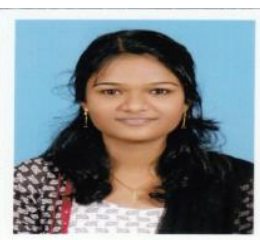

Madonna Jasmine J U, M.Tech (Construction Engineering and Management) SRM University, Chennai.

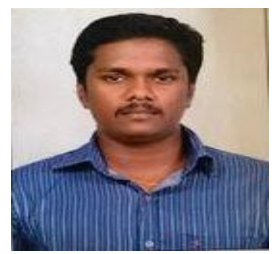

Mr.K.S.Praveen, Assistant Professor, Department of Civil Engineering, SRM University, Chennai. 